Pre-publication version: January 2013

\title{
Scholarly Publishing and the Internet: A NM\&S Themed Section
}

\author{
Nicholas W. Jankowski \\ e-Humanities Group, Royal Netherlands Academy of Arts and Sciences \\ Steve Jones \\ University of Illinois at Chicago
}

Note: This is a pre-publication version of the text introducing the New Media \& Society themed section on scholarly publishing. The published version of this text, together with the four articles, are available at SAGE OnlineFirst, and the print version of the collection is scheduled for publication in May 2013 (Volume 15, Number 3); see SAGE site for NM\&S. Please consult the published version for citation purposes.

\begin{abstract}
As co-editors of this themed section of New Media \& Society, we introduce the four articles comprising the section and briefly address facets of the changes transpiring in scholarly publishing and, more generally, scholarly communication. A plethora of issues and developments is related to this transformation and we suggest the diversity and challenges involved. We mention one development in more detail, enhanced publishing, and conclude with promising inroads for theoretical understanding and empirical investigation of how scholarly publishing and communication are evolving.
\end{abstract}

\section{Keywords}

scholarly publishing, scholarly communication, enhanced publishing, social media and scholarship

\section{Introduction}

There is ongoing tulmut in the world of scholarly publishing, which has been a matter of concern among stakeholders in the enterprise - scholars, editors, publishers, librarians, university administrators, funding agencies - for decades (e.g., Calabrese, 1992; Peek and Newby, 1996; Roberts, 1999). The concern has become more acute since widespread digitalization and the popularization of the Internet. Discussion of a few of the issues - manuscript review, access to publications and to data - has reached a white heat in some circles (Beall, 2012; reactions to the Finch Report, 2012, e.g., Brembs, 2012; Harnard, 2012), and seems concurrent with expansion of the open access movement and revolt among scholars and librarians to escalating costs of scientific periodicals in an increasingly restrictive financial climate for universities (e.g., Willinsky, 2006; Suber, 2012). Concurrent with debate on access and pricing, is increasing development of tools and support mechanisms for Web-based publishing, which also contributes to both the challenges facing and initiatives undertaken in scholarly publishing.

Many issues are interwoven in this tulmut, and numerous scholars have devoted extensive study to untangling the topics as they relate to academic publishing (e.g., Thompson, 2005; Campbell et al., 2012) and more specifically journals (Cope and Phillips, 2009), peer review (e.g., Weller, 2001; Fitzpatrick, 2011; Swan, 2012), social media and scholarship (Procter et al., 2010a, 2010b; Rowlands et al. 2011), and scholarship in a networked environment (e.g., Borgman, 2007; Nentwich and König, 2012; Nielsen, 2012). While much has already been written, New Media \& Society (NM\&S) felt the moment opportune to solicit a small number of contributions by observers, both scholars and practitioners. This themed section of NM\&S constitutes four articles that reflect on some of the 
challenges and initiatives presently facing scholarly publishing and, more generally, scholarly communication.

These four articles emerged from contributions prepared for two events: a roundtable discussion at the 2010 annual conference (IR11) of the Association of Internet Researchers (AoIR) in Goteburg, Sweden, and a panel held at the 2011 iCS / OII Symposium 'A Decade in Internet Time', Oxford University, UK. The first of these events involved seven participants who addressed aspects of peer review, commercial publishing, financing, and openness in science. The event generated much interaction between the roundtable participants and the audience. Traces of that discourse are reflected in the position statements of the participants, which are archived on a Website constructed for the event, Scholarly Publishing in the Digital Era.

The second of these events, a panel at a symposium co-organized by the journal Information, Communication \& Society (iCS) and the Oxford Internet Institute (OII), also has a Website Scholarly Communication: Changes, Challenges \& Initiatives - where various materials related to the topic can be found: publications, blog posts, links to videos and Websites. In addition to the conventional conference format of presentations and discussion with audience members, the panel organizers attempted to engage the audience in and outside the venue via a Twitter feed. Arrangements were made with John Willinsky at Stanford University who, unable to personally attend the symposium, composed tweets during during the 90-minute session. Willinsky followed the presentations via Skype and tweeted more than 40 summary statements. Clifford Tatum, co-organizer of the panel, sketched a diagram of the communication channels for the event; see Figure 1. The figure suggests the range of communication opportunities made available; in actuality, few attendees intervened via Twitter. In many respects, the discourse was similar to that at most traditional conferences: limited interaction between panelists and the onsite audience. ${ }^{1}$

These two events constituted the backdrop for this NM\&S themed section, published at SAGE OnlineFirst almost a year after the iCS / OII symposium. The manuscripts were subjected to onedirection blind peer review as well as a form of open peer review, making use of the WordPress plugin Digress.it. As is common with $\mathrm{NM} \& \mathrm{~S}$ articles, the manuscripts underwent multiple revisions and, in some cases, multiple rounds of review.

\section{ICS / OII Symposium A Decade in Internet Time, 21-24 September, Oxford \\ Scholarly Communication: Changes, Challenges \& Initiatives Symposium panel \& NM\&S theme issue}
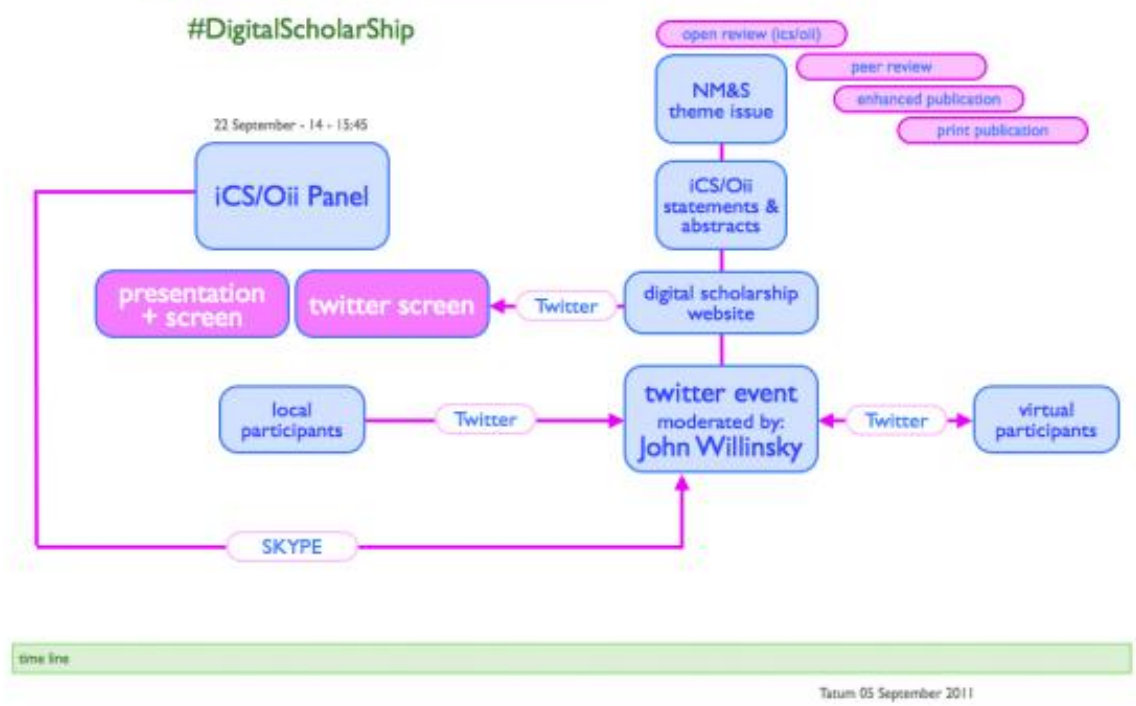

Figure 1: Schematic of Components for Panel on Scholarly Communication Source: Tatum, 2011 


\begin{abstract}
Articles
The first article in the section is by Phil Pochoda who presents a perspective drawing from his long career in publishing, including directorship of the University of Michigan Press. He suggests that the analogue publishing system has now been replaced by one mainly digital in nature. More substantial than this relatively technical transformation, Pochoda argues that the new publishing arena is radically different from traditional publishing: it is unbounded, amorphous, and very much in flux. Pochoda claims this situation is the basis for an epistemic shift. Borrowing a metaphor popular with seismologists, he suggests that the ongoing changes in scholarly publication may reflect a major transformation comparable to 'the big one'.
\end{abstract}

The second article, co-authored by Sophia Acord and Diane Harley, draws on a multi-year research project entitled the Future of Scholarly Communication and conducted under the auspices of the Berkeley Center for Studies in Higher Education. While the project was wide-ranging and resulted in diverse reports (e.g., Harley, 2010; Harley and Acord, 2011), this article concentrates on the uptake of new media for sharing and for openness in scholarly communication. Findings from scholars at different career stages and academic areas suggest that the uptake of new media is limited; differences largely relate to disciplinary cultures and more idiosyncratic aspects such as credit received, time available and researcher personality. Acord and Harley conclude by suggesting that notions from anthropologist Mary Douglas on the maintenance of classifications within different social categories may help understand the (lack of) uptake of social media in scholarly communities. It may be, in fact, that fragmentation of traditional social networks combined with proliferation of online social networking impede interdisciplinary exchange - a possibility that the authors feel merits consideration in future investigations on the transformation of scholarly communication.

The third article, prepared by John Willinsky and Johanne Provençal, presents an historical analysis of features of scholarship in monastaries during the Middle Ages. Some of the features of this period in scholarship - patronage, environment for study, and communality - contributed to what the authors more generally term the intellectual properties of learning. Willinsky and Provençal suggest parallels to the modern-day university system, particularly the tension between constraints imposed through private and institutional forms of sponsorship and more general objectives of learning. The authors argue for exploration of innovations in scholarship made possible during the digital era that facilitate the ideals of learning. Two such innovations are the repositories of scholarship established by many universities and the growing assortment of tools for academic publishing, such as those made available by the Public Knowledge Project.

The fourth and final contribution to this themed section is prepared by a team of UK researchers James Stewart, Rob Procter, and Robin Williams - that explores Web 2.0 innovations developed by two distinctly different scholarly publishers, Nature Publishing Group (NPG) and the Public Library of Science (PloS). This study complements an earlier investigation commissioned by the Research Information Network (RIN) that focused on the uptake of social media by researchers (Procter et al., 2010b). In this contribution the authors explore the strategies and constraints experienced by publishers involved in developing innovations within a Web 2.0 environment. While both of the publishers studied have played an important role in generating such innovations, they also have been restricted by a degree of indifference and sometimes resistance from users. For publishers, the authors suggest that a 'perpetual beta' approach to innovations may help identify user disposition at an early stage, and this awareness may be more beneficial to successful innovations than sheer size and available resources of a publishing house.

\title{
Other developments
}

While it is not possible within this introduction to discuss the large number of innovations ongoing in scholarly publishing, it would be remiss not to acknowledge however briefly some of the more prominent and recent developments such as a hybrid publishing model crafted by the University of Michigan Press and adapted by other university presses and some commercial enterprises (e.g., Bradley et al., 2011). ${ }^{2}$ Some publishers have initiated experiments with social media, such as the sites Communicationspace and Socialsciencespace developed by SAGE Publications. New initiatives with 
open access book publishing are emerging as are tools for this purpose, such as the Open Monograph Press (OMP) developed by the Public Knowledge Project. ${ }^{3}$ The recently formed Office of Scholarly Communication of the Modern Language Association announced the alpha version of a platform, MLA Commons, intended to be operational in early 2013 and designed to facilitate new formats in publishing. ${ }^{4}$ And, a broad coalition of scholars and publishers has composed a manifesto for change. Called Force11 (the Future of Research Communications and e-Scholarship), the Website of this initiative is becoming a rich repository of materials and discussion.

Somewhat related to the aspirations of Force11 is concern about 'enhanced publishing', an initiative to incorporate Web functionalities into scholarly publishing. ${ }^{5}$ While it is increasingly common for authors and sometimes publishers to prepare informational Websites to accompany books, it is less common for Web 2.0 functionalities to be included, such as blogs, and other interactive communicative services. It is even less common to encounter Web 3.0 or Semantic Web functionality, providing interoperability between, for example, the references in a publication with the content of those references. Jankowski et al. (2012) present an overview of enhanced publishing and report on an effort to develop a prototype for book monographs. Figure 2 suggests the interrelation between individual book Websites and their content, and connections to other Web-based materials.

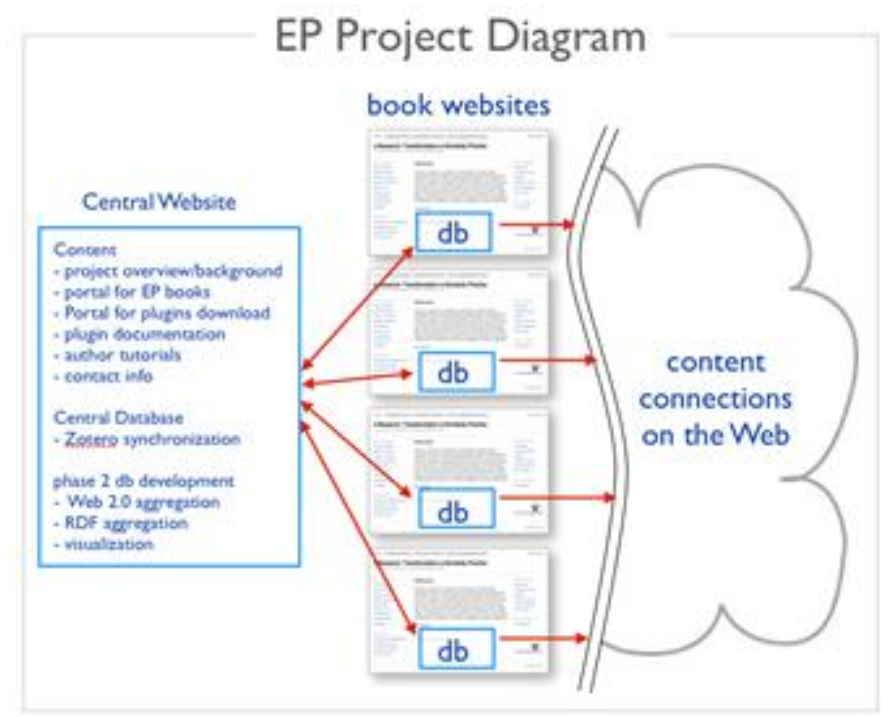

Figure 2: Schematic diagram of project Enhancing Scholarly Publishing Source: Jankowski et al. (2012: 9)

\section{Theoretical grounding}

While the above-mentioned initiative regarding enhanced publishing is practically-oriented and focuses on technical aspects of interoperability, it is grounded in a theory of communicative openness and draws on work by Merton (1979) and the interplay of formal and informal spheres of communication in scholarship (Garvey, 1979). The relation between interface and infrastructure of openness, along with the associated concepts, are illustrated in Figure 3 and are conceived as structural manifestations of human action involved with creating and using digital communication media. 


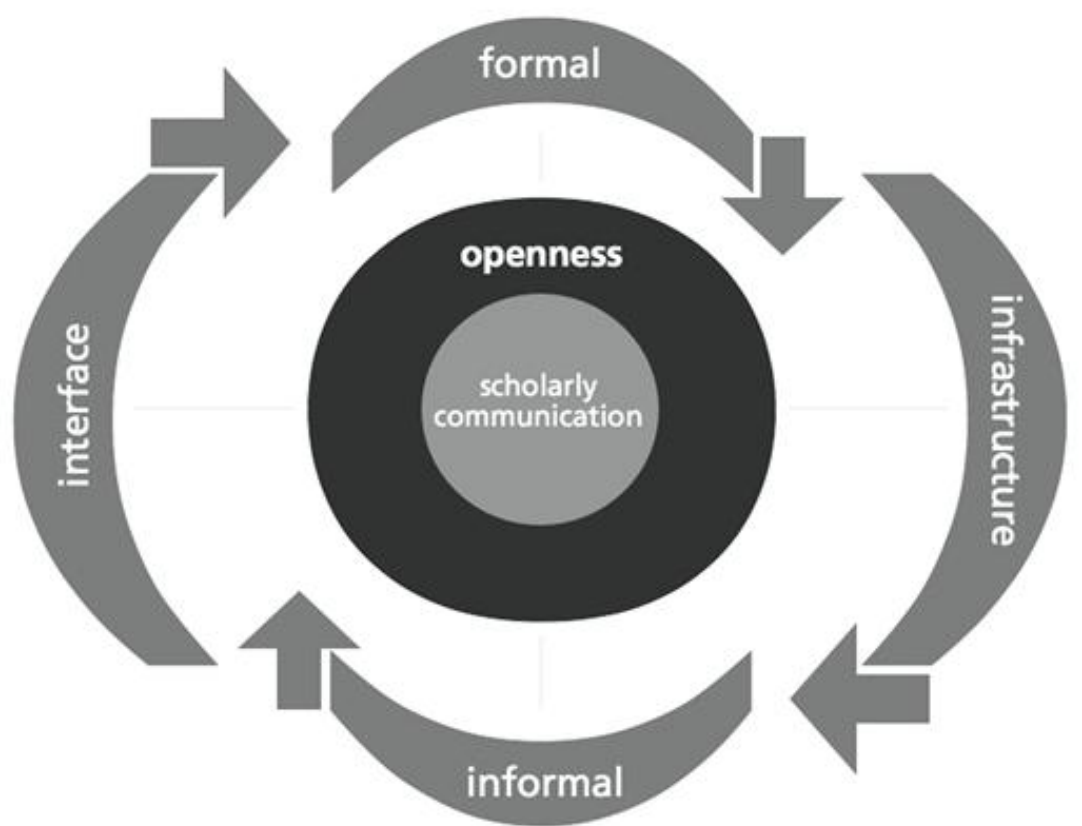

Figure 3: Diagram of Openness Framework

Source: Tatum and Jankowski, 2012: 194

Many other theoretical perspectives and concepts are applicable to understanding transformation in scholarly publishing and communication. The diffusion of innovations, for example, is a wellestablished approach and has been recently considered in new media settings (Danowski et al., 2011); it is also one of the approaches used by Stewart, Procter, Williams, and Poschen in their case studies of two publishers presented in this NM\&S themed section (Stewart et al., 2012). Space does not permit an extended overview of perspectives and models; that is an exercise more fitting for a review of the literature in a $\mathrm{PhD}$ dissertation, and Mackenzie Owen (2005) provides such in 'The scientific article in the age of digitalization'. The review acknowledges a common formulation (e.g., Rowland, 1997; Ware and Mabe, 2009: 12) of basic functions of scholarly publishing (registration,

disseminating, certification, archival record), and subsequent refinement of these functions. $\mathrm{He}$ criticizes various conduit models of communication and elaborates his own phase mode; see Figure 4. While this model benefits by identification of activities taking place at different stages in the research process, it does not suggest the cyclic nature of research and the blend of informal and formal communication activities that transpires at different points in the cycle. ${ }^{6}$ 


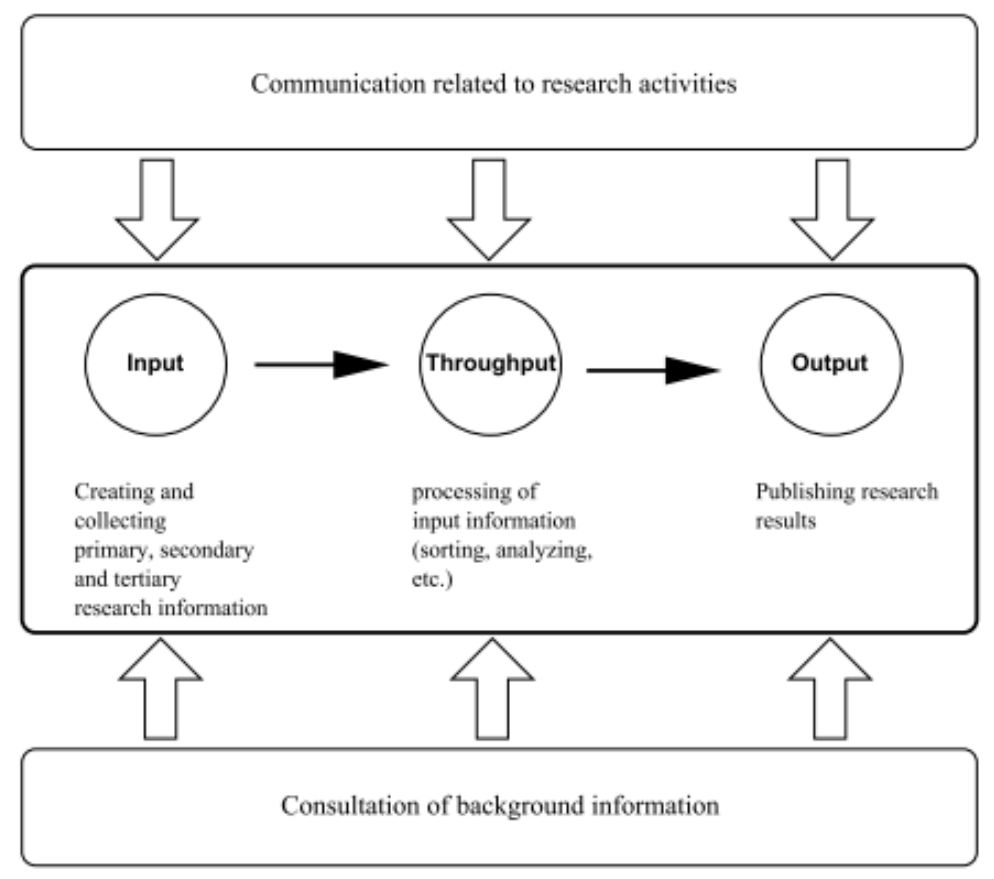

Figure 4: Three-phase model of research

Source: Mackenzie Owen (2005: 100)

\section{Next Steps}

In keeping with the overall objective of NM\&S to contribute to theoretically and empirically-based understanding of new media developments, it is appropriate that we note areas for further research. The authors to the articles in this themed section have done this for their respective approaches; our purpose is to suggest a few overarching queries that merit attention. Research agendas have been developed elsewhere by representatives from different disciplines. For example, in 2007 the Association of College \& Research Libraries (ACRL, 2007) prepared such an agenda and identified eight themes relevant to librarianship. A similar agenda from the disciplinary perspective of media and communication studies has not, to our knowledge, been compiled, but probably would contain clusters of research questions related to the traditional - and intertwined - components of the communication process: sender, content, receiver, and context. Myriad models have been constructed with these and more elaborate constructs, and are addressed in detail elsewhere (e.g., McQuail and Windahl, 1993). ${ }^{7}$ While the specificities of these models may not be entirely relevant to scholarly communication in a networked environment, the four above-mentioned components can serve as a clustering mechanism for research interests. Below are illustrations of guiding questions for each of these components:

- Sender (i.e., author, publisher): In what ways, with what intentions and accomplishments, do authors and publishers incorporate informal communication channels into overall strategies for formal scholarly communication?

- Content: How are functionalities of Web 2.0 and the Semantic Web introduced into scholarly publications, with what differences between disciplines?

- Receiver (i.e., reader): What uses (and gratifications) do different categories of the readers of journal articles (e.g., students, researchers) make of publisher-provided functionalities to online versions of journal articles (e.g., social bookmarking, reference management systems)?

- Context: How are institutions (e.g., universities, funding agencies, governmental offices) mandating access to publications and data, with what challenges?

Such questions can be addressed in various ways, but focused case studies, comparative in nature and across time, offer much potential for understanding the ongoing changes in scholarly communication. This is basically the approach for the research conducted by contributors to this themed section (e.g., Acord and Haley, 2012; Stewart et al., 2012). A case study approach is also undertaken in two 
Research Information Network (RIN) studies (Bulger et al., 2011; Meyer et al., 2011) on the uptake of social media across disciplines and institutions. While these studies were limited in scope and exploratory in nature, the mapping exercises poignantly visualize the differences found between cases in the humanities and those in the natural sciences; see Figures 5 and 6. These visualizations beckon for further substantiation and elaboration about how scholarly cultures contribute to communication practices in a networked environment along axes reflecting degrees of computational complexity and collaboration. In terms of a research agenda on the transformation of scholarly communication, these visualizations and the studies on which they are based provide much promise.

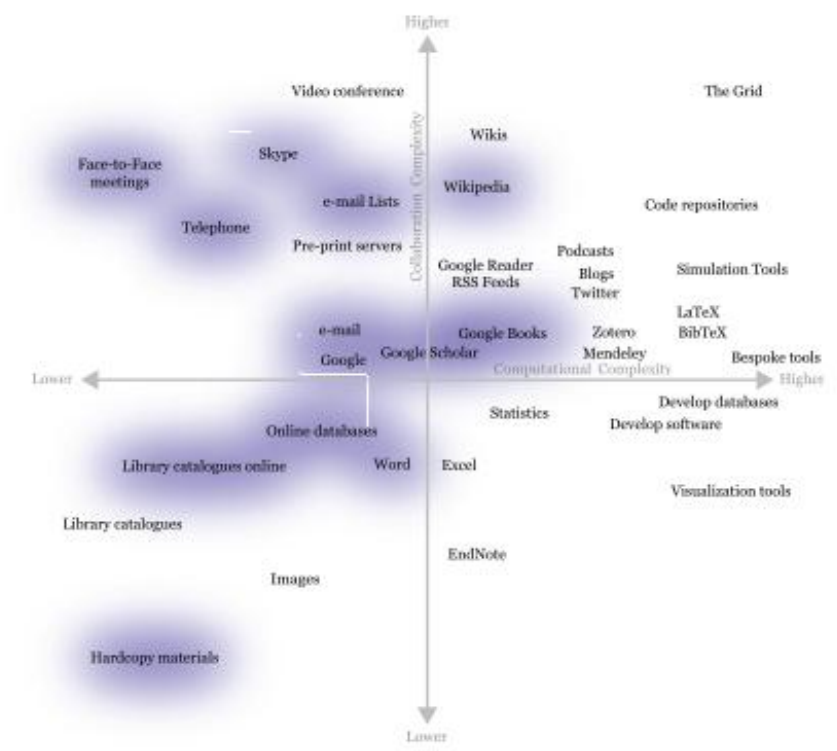

Figure 5: Humanities complexity continuum

Source: Meyer et al. (2011: 81)

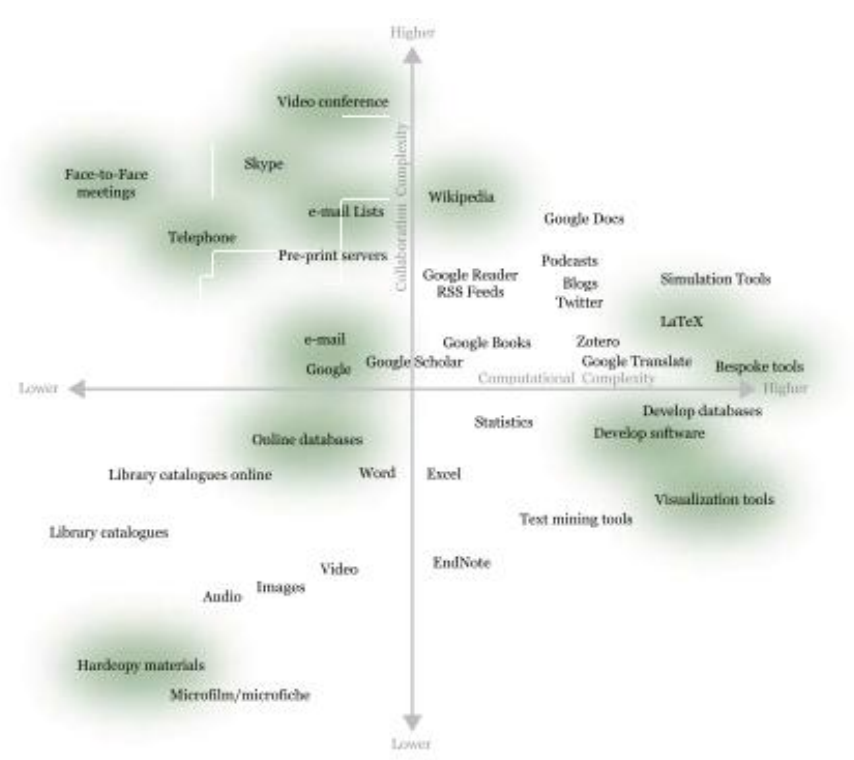

Figure 6: Physical sciences complexity continuum

Source: Meyer et al. (2011: 80)

In conclusion, we wish to endorse the initiative taken by John Willinsky and Johanne Provençal in making their article available at the Stanford University repository. Other authors of the articles in this themed section have taken similar steps with institutional repositories and we are following their lead by placing this introductory essay in the University of Illinois at Chicago repository, INDIGO. In 
addition to increasing access to the results of scholarship through repositories of publications, we feel collaborative sharing at early stages of scholarship important, as is made possible through the social bookmarking functions of some reference management systems, particularly the services Zotero and Mendeley. To this end we have created an open group on Mendeley entitled 'Scholarly Communication: Theory and Research, Policy and Practice' where the resources compiled for this essay (e.g., annotations and references) and other projects (e.g., Tatum and Jankowski, 2012; Jankowski et al., 2012) are deposited. We hope these materials might contribute to the endeavors of others in exploring future directions of scholarly communication. Finally, some of the authors to this $N M \& S$ themed section have prepared podcasts on their work; these can be viewed at SAGE Podcast and at the $N M \& S$ website.

\section{Acknowledgements}

We wish to thank those scholars that contributed to the IR11 conference Roundtable and iCS / OII symposium panel on scholarly communication: IR11: Kathleen Fitzpatrick, Alex Halavais, Stu Shulman, Siva Vaidhyanathan, and Clifford Tatum; iCS / OII: Clifford Tatum, Christine Borgman, Philip Pochoda, Rob Procter, Paul Wouters, and John Willinsky. Clifford Tatum, co-organizer of these two events, also prepared accompanying Websites for which we are grateful. The Virtual Knowledge Studio and the eHumanities Group, both initiatives of the Royal Netherlands Academy of Arts and Sciences, provided a welcome home during preparation of the above events and exploration of a facet of scholarly communication, enhanced publications. Finally, we extend our thanks to the authors that contributed to this themed section for their patience and comments on a preliminary draft of this introductory essay.

\section{References}

Acord SK and Harley D (2012) Credit, time, and personality: Incorporating disciplinary needs and values into predictions about the future of scholarly communication. New Media \& Society. Available at:

http://nms.sagepub.com/content/early/2012/12/20/1461444812465140.abstract (accessed 25 November 2012).

Beall J (2012) Predatory publishers are corrupting open access. Nature 489: 179. Available at: http://www.nature.com/polopoly fs/1.11385!/menu/main/topColumns/topLeftColumn/pdf/48 9179a.pdf (accessed 31 October 2012).

Borgman CL (2007) Scholarship in the Digital Age: Information, Infrastructure, and the Internet. Cambridge, MA: MIT Press.

Bradley J, Fulton B, Helm M and Pittner KA (2011) Non-traditional book publishing. First Monday, 16: 8. Available at: http://firstmonday.org/htbin/cgiwrap/bin/ojs/index.php/fm/article/viewArticle/3353/3030 (accessed 31 October 2012).

Brembs B (2012) The Finch Report illustrates the new strategy wars of open access. Blog post 2 July, LSE Impact of Social Sciences. Available at:

http://blogs.lse.ac.uk/impactofsocialsciences/2012/07/02/strategy-wars-open-access/ (accessed 31 October 2012).

Breure L, Voorbij H and Hoogerwerf M (2011). Rich Internet publications: 'Show what you tell'. Journal of Digital Information 12(1). Available at: http://journals.tdl.org/jodi/article/view/1606/1738 (accessed 30 October 2012).

Bulger M, Meyer ET, de la Flor G, Terras M, Wyatt S and Jirotka M (2011) Reinventing research? Information practices in the humanities. Report. London: Research Information Network. Available at: www.rin.ac.uk/humanities/case-studies (accessed 30 October 2012).

Calabrese A (1992) Changing times for scholarly communication: The case of the electronic journal. Technology in Society 14: 199-220. Available at: 
http://spot.colorado.edu/ calabres/Changing\%20Times\%20for\%20Scholarly\%20Communicat ion.pdf (accessed 31 October 2012).

Campbell R Pentz E and Borthwick I (eds) (2012) Academic and Professional Publishing. Oxford, UK: Chandos Publishing.

Cope B and Phillips A (eds) (2009) The Future of the Academic Journal. Oxford, UK: Chandos Publishing.

Danowski JA, Gluesing J and Riopelle K (2011) The revolution in diffusion theory caused by new media. In: Vishwanath, A and Barnett, GA (eds) The Diffusion of Innovations: A Communication Science Perspective, New York: Peter Lang, 123-144.

Harley D and Acord SK (2011) Peer Review in Academic Promotion and Publishing: Its Meaning, Locus, and Future. University of California, Berkeley: Center for Studies in Higher Education. Available at: http://escholarship.org/uc/item/1xv148c8 (accessed 30 October 2012).

Harley D, Acord SK, Earl-Novell S, Lawrence S and King CJ (2010) Assessing the future landscape of scholarly communication: An exploration of faculty values and needs in seven disciplines, University of California, Berkeley: Center for Studies in Higher Education. Available at: http://escholarship.org/uc/cshe_fsc (accessed 30 October 2012).

Finch D (2012) Accessibility, sustainability, excellence: how to expand access to research Publications. Report of the working group on expanding access to published research findings. Available at: http://www.researchinfonet.org/wp-content/uploads/2012/06/FinchGroup-report-FINAL-VERSION.pdf (accessed 31 October 2012).

Fitzpatrick K (2011) Planned Obsolescence: Publishing, Technology, and the Future of the Academy. New York: New York University Press.

Garvey WD (1979) Communication, the Essence of Science: Facilitating Information Exchange among Librarians, Scientists, Engineers, and Students. Oxford: Pergamon Press.

Harnard S (2012) Why the UK should not heed the Finch Report. Blog post 4 July, LSE Impact of Social Sciences. Available at: http://blogs.lse.ac.uk/impactofsocialsciences/2012/07/04/whythe-uk-should-not-heed-the-finch-report/ (accessed 31 October 2012).

Jankowski NW (2009) The contours and challenges of e-research. In: Jankowski NW (ed) $e$ Research: Transformation in Scholarly Practice. New York: Routledge, 3-31.

Jankowski NW, Scharnhorst A, Tatum C and Tatum Z (2012) Enhancing scholarly publications: Developing hybrid monographs in the humanities and social sciences. Scholarly Research and Communication 4(1). Available at: http://src-online.ca/index.php/src/issue/current (accessed 30 November 2012).

Mackenzie Owen JS (2005) The scientific article in the age of digitization. PhD dissertation, University of Amsterdam. Available at: http://dare.uva.nl/record/167602 (accessed 31 October 2012).

McQuail D and Windahl S (1993) Communication Models for the Study of Mass Communications. London: Longman.

Merton RK (1979) The Sociology of Science. Chicago: University of Chicago Press.

Meyer ET, Bulger M, Kyriakidou-Zacharoudiou A, Power L, Williams P, Venters W, Terras M and Wyatt, S (2011). Collaborative yet independent: Information practices in the physical sciences. Report. London: Research Information Network. Available at: www.rin.ac.uk/humanities/case-studies (accessed 30 October 2012).

Nentwich M and König R (2012) Cyberscience 2.0: Research in the Age of Digital Social Networks. Frankfurt: Campus Wissenschaft.

Nielsen M (2012) Reinventing Discovery: The New Era of Networked Science. Princeton: Princeton University Press.

Peek, RP and Newby, GB (eds) (1996) Scholarly Publishing: The Electronic Frontier. Cambridge, MA: MIT Press.

Procter R, Williams R, Stewart J, Poschen M, Snee H, Voss A and Asgari-Targhi M (2010a) Adoption and use of Web 2.0 in scholarly communications. Philosophical Transactions of the Royal Society 368: 4039-4056.

Procter R, Williams R, Stewart J, Poschen M, Snee H, Voss A and Asgari-Targhi M (2010b) If you build it, will they come? How researchers perceive and use web 2.0. Report for the Research 
Information Network. Available at www.rin.ac.uk/our-work/communicating-and-

disseminating-research/use-and-relevance-web-20-researchers (accessed 30 October 2012).

Stewart J, Procter R, Williams R and Poschen M (2012) The role of academic publishers in shaping the development of Web 2.0 services for scholarly communication. New Media \& Society. Available at SAGE OnlineFirst: http://nms.sagepub.com/content/early/2012/12/04/1461444812465141.abstract (accessed 25 November 2012).

Roberts P (1999) Scholarly publishing, peer review and the internet. First Monday 4 (4). Available at http://firstmonday.org/htbin/cgiwrap/bin/ojs/index.php/fm/article/view/1287/1207 (accessed 30 October 2012).

Rowland F (1997) Print journals: Fit for the future? Ariadne, Issue 7. Available at: http://www.ariadne.ac.uk/issue7/fytton (accessed 30 October 2012).

Rowlands I, Nicholas D, Russell B, Canty N and Watkinson, A (2011) Social media use in the research workflow. Learned Publishing 24(3): 183 - 195.

Suber P (2012) Open Access. Cambridge, MA: The MIT Press.

Swan A (2012) Policy guidelines for the development and promotion of open access. Report. Paris: UNESCO.

Tatum C (2011) Formalization of informal scholarly communication. Paper presented at iCS-OII Symposium, A Decade in Internet Time. University of Oxford. available at http://digitalscholarship.ehumanities.nl/scholarly-communication/ics-oii-symposium-201/ (accessed 20 November 2012).

Tatum C and Jankowski NW (2012) Openness in scholarly communication: Conceptual framework and challenges to innovation. In: Wouters P, Beaulieu A, Scharnhorst A and Wyatt S (eds), Virtual Knowledge: Experimenting in the Humanities and Social Sciences. Cambridge, MA: MIT Press, 183-218.

Thompson JB (2005) Books in the Digital Age: The Transformation of Academic and Higher Education Publishing in Britain and the United States. Cambridge, UK: Polity.

Ware, M and Mabe, M (2009) The stm report: An overview of scientific and scholarly journal publishing. Oxford, UK: International Association of Scientific, Technical and Medical Publishers. Available at: http://www.stm-assoc.org/2009 10 13 MWC STM Report.pdf (accessed 30 October 2012).

Willinsky J (2006) The Access Principle: The Case for Open Access to Research and Scholarship. Cambridge, MA: The MIT Press.

Weller AC (2001) Editorial Peer Review: Its Strengths and Weaknesses. Medford NJ: ASIST Monograph Series.

Weller M (2011) The Digital Scholar. How Technology is Transforming Scholarly Practice. Hampshire, UK: Bloomsbury Academic.

\section{Authors}

Nicholas W Jankowski is Associate Researcher at the e-Humanities Group of the Royal Netherlands Academy for Arts and Sciences. He served as co-editor of New Media \& Society from 1999 through 2012. Jankowski is editor of e-Research: Transformation in Scholarly Practice (Routledge, 2009) and co-editor of The Long History of New Media (with David Park and Steve Jones, Peter Lang, 2011). Email: n.jankowski@xs4all.nl

Steve Jones is UIC Distinguished Professor of Communication, Research Associate in the UIC Electronic Visualization Laboratory, and Adjunct Research Professor in the Institute of Communications Research at the University of Illinois at Urbana-Champaign. He is author and editor of numerous books, and co-editor of New Media \& Society, co-editor of Mobile Media \& Communication, and edits Digital Formations, a series of books on digital media, the internet and communication (Peter Lang Publishing). He is a Fellow of the International Communication Association. 


\section{Notes}

${ }^{1}$ A map of the Twitter feed for the symposium, uploaded to the Website of this panel, suggests a diversified and relatively large volume of tweets for the symposium overall; see http://digitalscholarship.ehumanities.nl/scholarly-communication/ics-oii-symposium-201/ (accessed 30 October 2012).

${ }^{2}$ See, e.g., Bloomsbury Academic and illustrative title of hybrid publishing by Weller, 2011; initiative Palgrave Pivot launched 30 October 2012, Oxford Scholarly Editions Online (OSEO) launched 26 September 2012, Anvil Academic launched February 2012, OpenBook Publishers, and Ubiquity Press.

${ }^{3}$ The beta version of OMP was released September 2012; see Australian Science blog post. An overview of tools for open access publishing has been compiled by the Scholarly Publishing and Academic Resources Coalition (SPARC):

http://www.arl.org/sparc/publisher/journal_management.shtml (accessed 31 october 2012).

${ }^{4}$ News release of MLA Commons, 1 October 2012, available at: http://www.mla.org/news_from_mla/news_topic\&topic=671 (accessed 30 October 2012).

${ }^{5}$ Breure et al. (2011) suggest an alternative term, Rich Internet Publications, for basically the same development.

${ }^{6}$ A cyclic model is suggested in Jankowski (2009) and Tatum and Jankowski (2012).

${ }^{7}$ In fairness, it should be mentioned that the communication models presented by McQuail and Windahl (1993) relate to mass communication and not to those forms digital in nature and performed in a network environment. Nevertheless, features of some mass communication models, such as feedback and interactivity, are relevant to contemporary networked communication. 